\title{
CONTROLLING POWER PLANT BOILER AND DRAFT FAN USING LABVIEW
}

\author{
P. Hari Krishnan ${ }^{1}$, V.Ramprasadh ${ }^{2}$ \\ ${ }^{1}$ Assistant Professor, Department of EEE, Anna University Regional Centre-Coimbatore, Tamil Nadu, India \\ ${ }^{2}$ PG Scholar, Department of C\&I, Anna University Regional Centre-Coimbatore, Tamil Nadu, India
}

\begin{abstract}
In this proposed paper, design and controlling of the power plant boiler and draft fan which is currently working on DCS technique has been attained by employing high computing software LabVIEW. The intension of this work is to control the boiler, induced draft fan and forced draft fan in an innovative methodology. A set of inter mesh conditions were provided for this purpose. The aim was to enforce the controlling of boiler, induced draft fan and forced draft fan in LabVIEW that would control the boiler, induced draft fan and forced draft fan as like as the DCS technique. Since DCS is only efficient for large system not less than 5000 inputs and outputs. As above mentioned technique (DCS based) was not cost effective and also it consists of a separate server, a processor and a workstation whereas in the case of software based LabVIEW technique does not require aseparate server, processor and workstation and operator station.
\end{abstract}

Keywords: Boiler, Induced draft fan, Forced draft fan, LabVIEW.

****.

\section{INTRODUCTION}

Draft is defined as the deviation between atmospheric pressure and the static pressure. Draft is classified into natural and mechanical draft. A stack of compulsory height to cause the sufficient pressure difference creates natural draft with the resulting air and flue gas flows. Combustion gases are created when a fuel is burned in a boiler. These combustion gases are called flue gases as they are dispelled via the flues, which are the passes or ducts that associate the boiler with the stack.

Mechanical draft is partially created by the use of mechanical fans. They may push the air and ignition gases through the boiler, in these case they are called forced draft fans (F.D. fans). They may also pull the air and gases inside the boiler, in which case they are called induced draft fans (I.D. fans). When furnace draft is sustained at atmospheric pressure (or just below), by use of a combination of forced and induced draft fans, the draft is mentioned to as a balanced draft system.

\section{BOILER}

Boiler is an enclosed vessel in which water or other liquid is heated. The heated or vaporized liquid way out the boiler for use in various process or heating applications. It is a device utilized to generate steam by applying heat energy to water or other liquid. A boiler must be modeled to absorb the maximum amount of heat obtainable in the process of combustion of fuel. The heat is transferred to the boiler water or other liquid by radiation or conduction. The relative percentage is depend upon the type of boiler and the intention of the heat transfer surface and the type of fuel using.

\subsection{Drum Level Control System}

Drum Level Control Systems are used widely throughout the process industries. It is used to control the level of boiling water comprised in boiler drums and offer a constant supply of steam. If the level is too high, flooding of steam refinement equipment can occur. If the level is too low, reduction in efficiency of the handling and recirculate function. Pressure can also build to dangerous levels. A drum level control system controls the level regardless to the disturbances, increase/decrease of steam demand, feed flow variations. Boiler drum level control is censorious for the protection of plant and protection of equipment. The intension of the drum level controller is to take the drum level up to the given set point and to keep the level at constant steam load. A keen intense decrease in this level makes the boiler tubes to become overheated and damaged. An increase in this level may cause disturbance with the process of differentiating moisture from steam within the drum, thus the productivity of the boiler reduces and transmit moisture into the turbine. Normally, there are three scheme used to control drum level. With each successive scheme, an elaboration of the previous control scheme has been taken place. For extent of the load change requirements, the control scheme depends on the measurement and control equipment.

\subsection{Single Element Control}

The single element control is the simplest method for boiler drum level control system. In this systematic way of drum level control needs a measurement of drum water level and feed water control. It is mainly recommended for boiler with tolerable change requirement and relatively constant feed water condition. The process variable coming from the drum level transmitter is equate to a set point and the difference is 
called as deviation value. This signal is supplies to the controller which produce restorative action output. The output is then passed to the boiler feed water valve, which regulate the level of feed water flow into the boiler drum. If The steam flow limit and feed water flow limit were equaled so that a one pound deviation in steam flow results in a one pound change in feed water flow. The addition combines the steam flow signal with the feedback action of the drum level controller which makes clip adjustments in feed water flow, as required, to remunerate for unmeasured blow down losses and steam flow measurement errors.

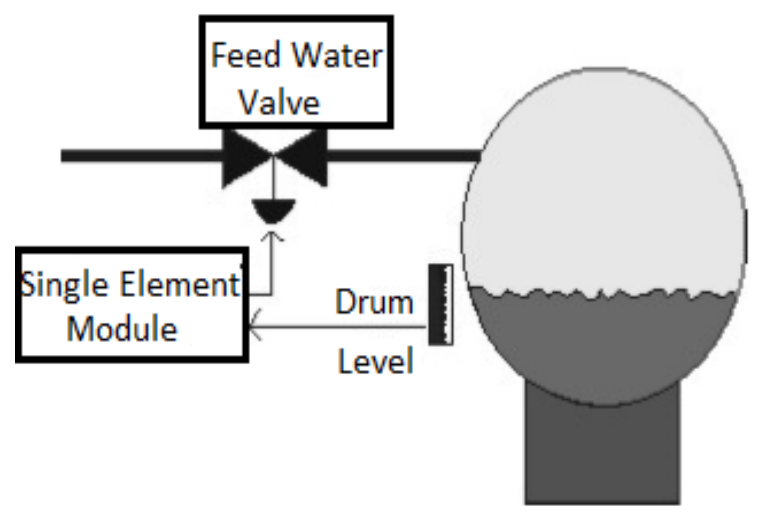

Fig-1: Single Element Control

\subsection{Induced Draft Fan}

Method of producing mechanical draft is the induced draft system. This consists of a fan which installed between the boiler and the stack. This fan pulls the flue gases through the boiler and pushes them up the stack. A pressure inside the furnace is slightly lower than atmospheric pressure is created in the boiler. It is necessary that the boiler casing and openings are sealed to prevent air leaking into the boiler, which would quickly lower the capacity and efficiency of the fans. The boiler casings is essential to be build strong enough to withstand the external pressure of the atmosphere.

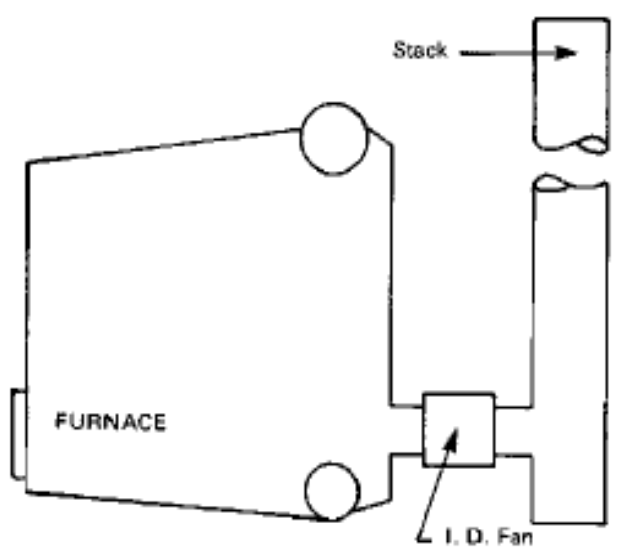

Fig -2: Induced Draft Fan

\subsection{Forced Draft Fan}

These fans are driven by a steam turbine or by using electric motor. A common method of the forced draft system, in which the fan delivers air along an air duct to an enclosed furnace front When utilizing a forced draft system the whole furnace casing is under a positive pressure. To stop the leakage of gases the furnace and every furnace openings must be carefully plastered against outward leakage.

\section{DEVELOPMENT USING LabVIEW}

Execution is decided by the structure of a graphical block diagram (the LV-source code) on which the programmer associates different function-nodes by practicing drawing wires. These wires produce variables and any node can execute as soon as all its input data were getable. Since this might be the example for multiple nodes at the same time, $G$ is essentially accomplished of synchronic execution.

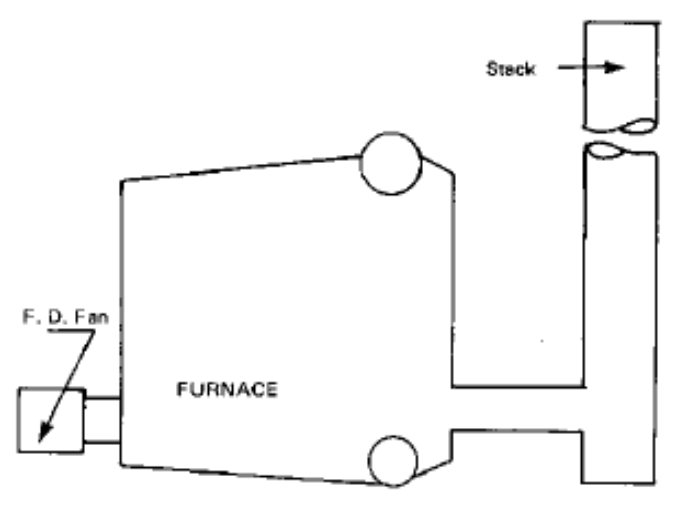

Fig -3: Forced Draft Fan

\subsection{Graphical Programming}

LabVIEW is the innovation for user interfaces (called front panels) into the exploitation cycle. LabVIEW subroutines are called virtual instruments (VIs). Each VI has three components: a block diagram, a front panel, and a connector panel. Controls and indicators on the front panel permits the operator to enter data into or fetch data from a running VI. The front panel can also assist as a program interface. Thus a virtual instrument can be perform as a program, by the help of front panel which process as a user interface, or by dropped as a node onto the block diagram, the front panel determine the inputs and outputs for the given node applying the connector pane. The graphical programming also permits non-programmers to shape programs basically by dragging and dropping virtual representations of lab equipment with which they are so soon known.

\section{SIMULATION AND RESULT}

\subsection{The Logic}

In this paper for regulating boiler, induced draft fan and forced draft fan. Set of six interconnect parameters were taken for both induced draft fan and forced draft fan and four important parameters for boiler. The logic for the 
induced draft fan to be in ON condition, were both inlet damper and inlet guide vane should be in closed position and the temperature of induced draft fan bearing, induced draft fan winding, induced draft fan motor bearing and induced draft fan motor winding should be in low level. Throughout the operation, if any of the above declared conditions goes out of the limit then the induced draft fan trip to OFF condition and stack cap will modify to open position. These conditions are comparable for forced draft fan also. The logic for the boiler to be in ON condition were together induced draft fan and forced draft fan should be in normal. Boiler feed water temperature, boiler pressure, makeup water temperature, fuel volume have to be in controlled level, and during the measured operation if any of the above acknowledged four conditions goes out of the limit boiler will ends functioning.

\subsection{Design of Control System using LabVIEW}

The procedure of virtual instrument technology, complete the LabVIEW software to accomplish control of boiler, induced draft fan, forced draft fan the block diagram of control system were shown in Fig. 4, Fig. 5 and Fig. 6.

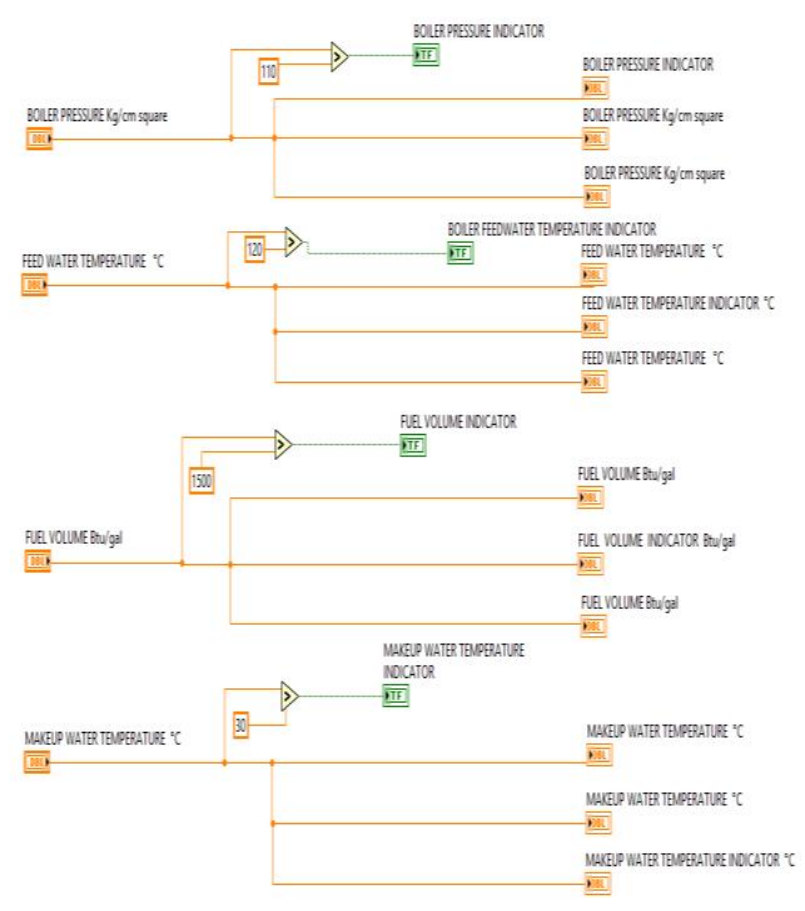

Fig-4: Block diagram of boiler parameters

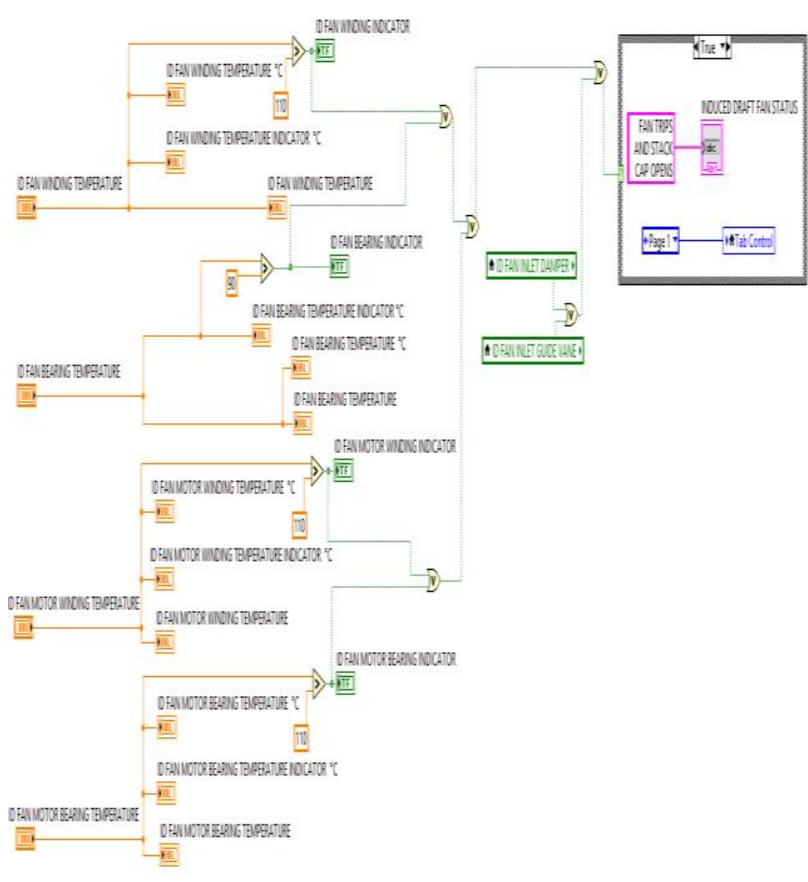

Fig-5: Block Diagram of induced draft fan winding parameters

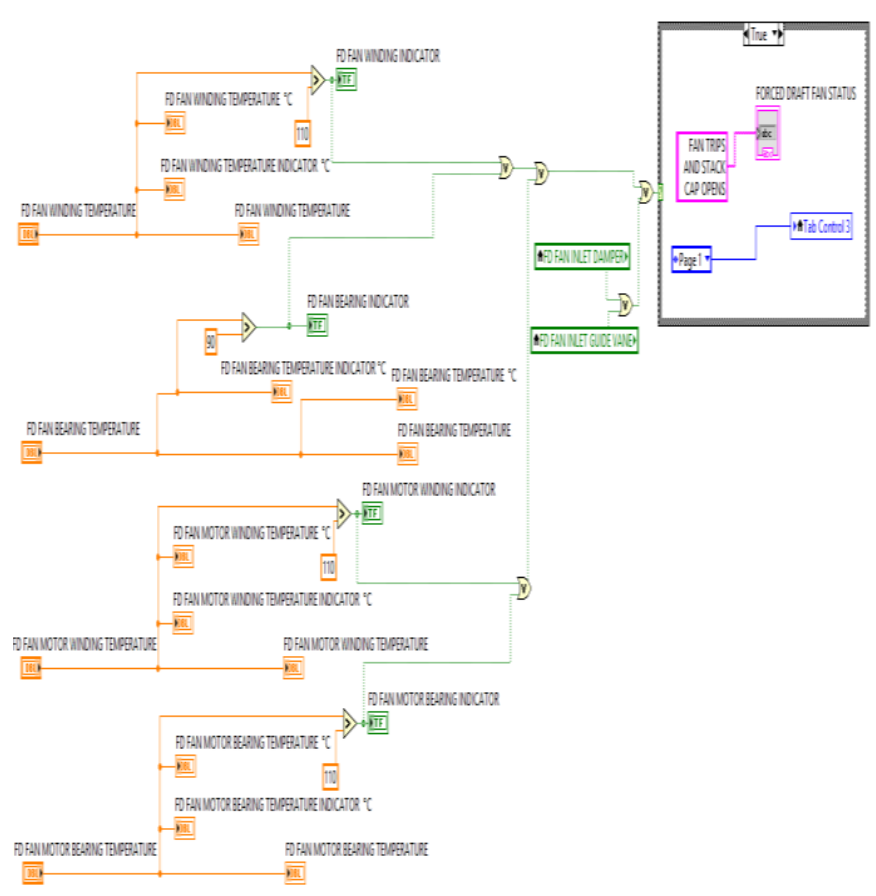

Fig-6: Block diagram of forced draft fan winding parameters

In LabVIEW, It have been established a user front panel, with controls and indicators. Controls simulate input devices and fund data to the block diagram. Front Panel for boiler parameters, Induced draft fan parameters and Forced draft fan parameters were considered and shown in Fig. 7, Fig. 8 and Fig. 9. 


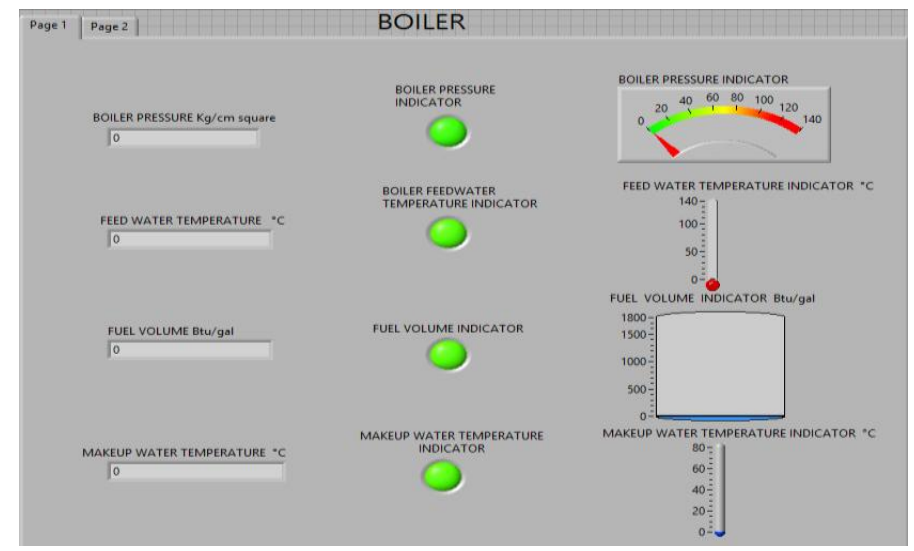

Fig-7: Front Panel of boiler parameters

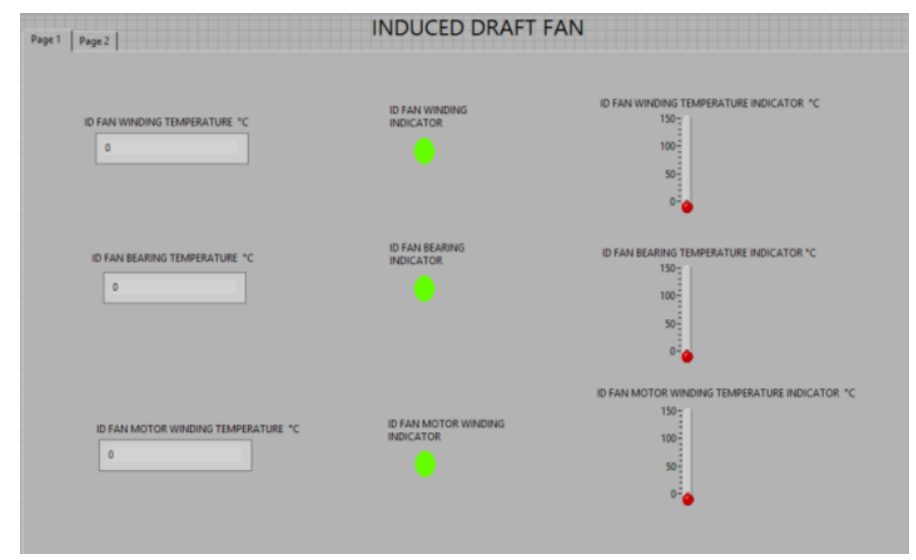

Fig -8: Front panel of induced draft fan winding parameters

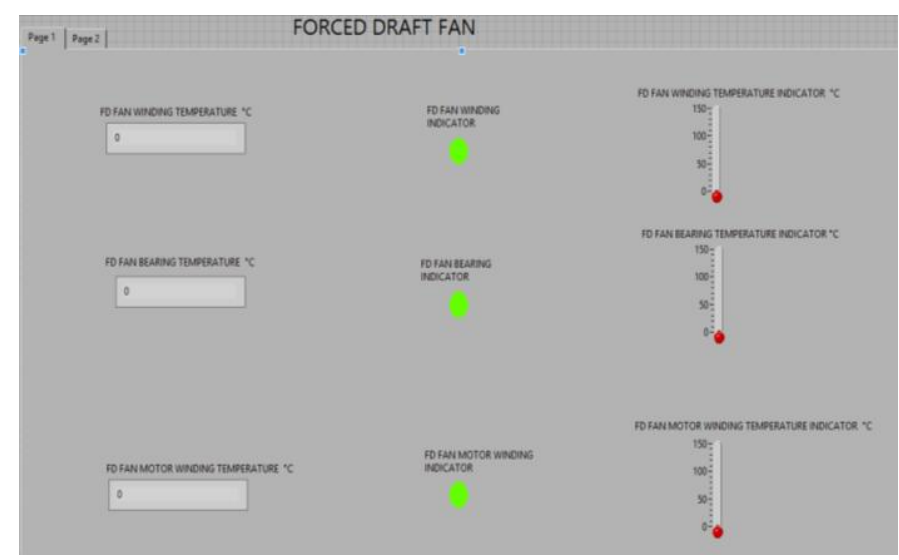

Fig -9: Front panel of forced draft fan winding parameters

\subsection{Results}

The Induced draft fan are in ON condition, because inlet damper and inlet guide were in closed position and the temperature of induced draft fan bearing, induced draft fan winding, induced draft fan motor bearing and induced draft fan motor winding parameters are in level underneath the set point. So the induced draft fan positiondisplays normal is shown in Fig.10. Outcome of induced draft fan winding parameters. And this process is comparable for forced draft fan which is also normal and result is shown in Fig.11. Result of forced draft fan winding parameters.

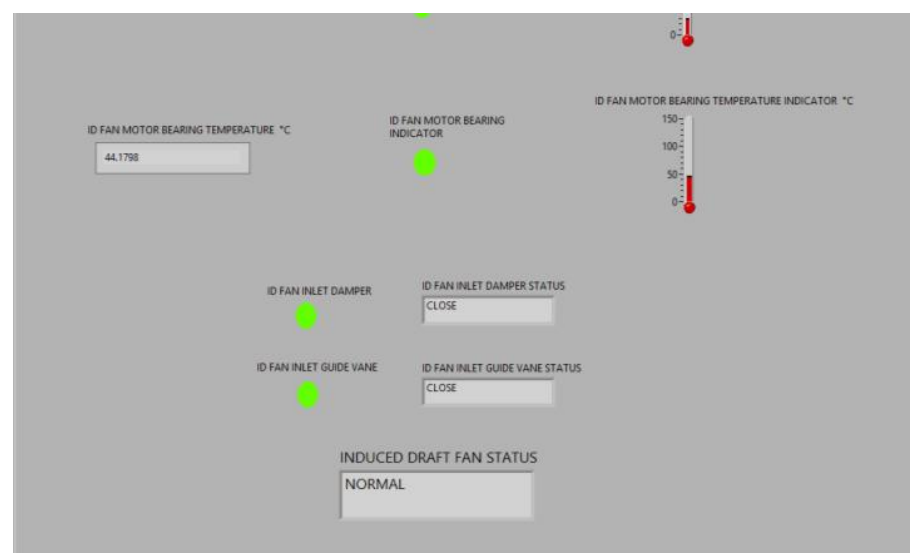

Fig-10: Results of induced draft fan winding parameters

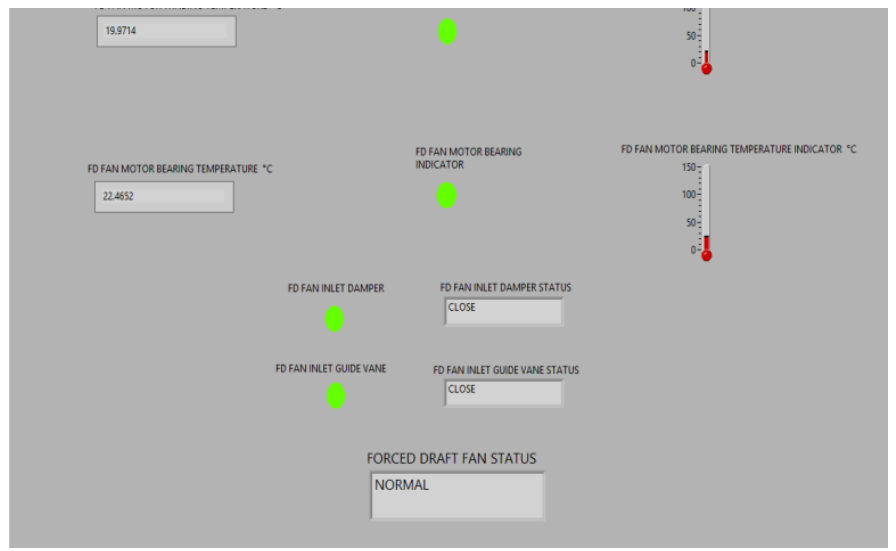

Fig-11: Results of forced draft fan winding parameters

The Boiler are in ON condition, since both induced draft fan and forced draft fan were in normal condition and boiler feed water temperature, boiler pressure, makeup water temperature, fuel volume parameters were in level underneath the set point. So the boiler status displays normal, are shown in Fig.12. Results of boiler parameters.

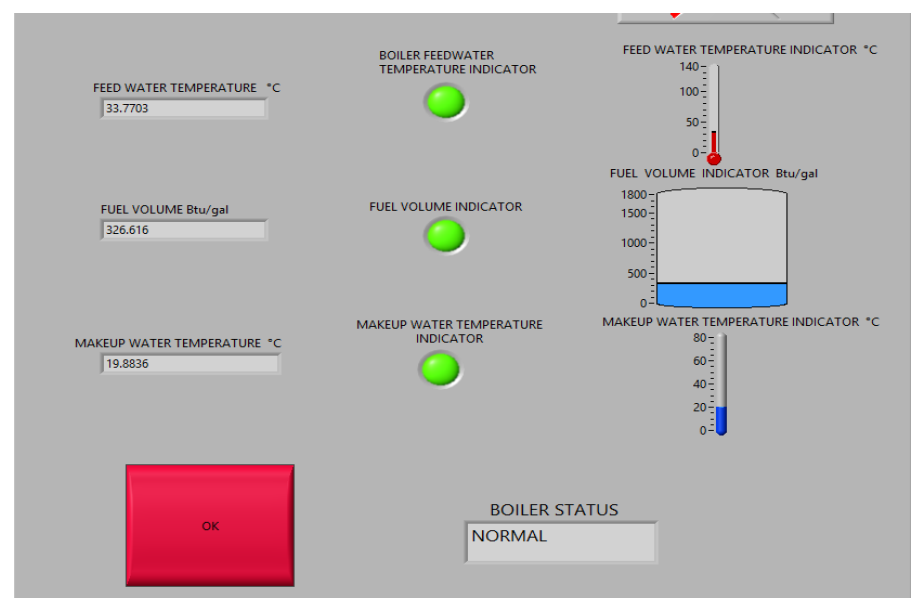

Fig-12: Results of boiler parameters 


\section{CONCLUSIONS}

Established on the graphical programming language and the data stream functioning mode, the software in its place of apparatus, the training of virtual instrument technology has opened up our innovative field of control. Associated to the outdated control it has understandable advantages. Programming is simple by the graphical programming language. A panel of LabVIEW distinguishes button design and layout, with the virtual handles and changes to the approachable human, instinctive control interface makes vivid, so that the operators are elaborate in the operation at ease to regulate the process and results at a glance. The main improvement of controlling Boiler, Induced draft fan and Forced draft fan by means of LabVIEW is reduced cost as compared to DCS method, since the interfacing of inputs and outputs are directly given to the PC.

\section{ACKNOWLEDGEMENTS}

I would like to acknowledge and prolong my heartfelt gratitude to my guide-Assistant Professor P. Hari krishnan, for his vital encouragement and patience guidance, generous assistance and invaluable advice, all of which have been of inestimable worth to the accomplishment of my paper.

Finally, my thanks would also go to my beloved parents for me boundless love and whole-hearted support over all these past years.

\section{REFERENCES}

[1] Gregory K.McMillan, Douglas M.Considine (Ed), Process/Industrial Instruments and Controls Handbook Fifth Edition, McGraw-Hill, 1999 ISBN 0-07-012582-1 Section 3 Controllers

[2] IEEE Guide for AC Motor Protection IEEE, Std C37.96-2000 (Revision of IEEE Std C37.96-1988)

[3] Li, Nan; Teng, Fei System Design Electro-motor Rotational Speed Control Based on of LabVIEW. Computer Measurement \& Control, p794-799. 2006. 14(6).

[4] Min Xu, Shaoyuan Li, WenjianCai, "Cascade generalized predictive control strategy for boiler drum level" ISA Trans. vol. 44 issue 3, pp. 399-404, July 2005.

[5] Prime, J.B. Valdes, J.G., "use of ladder diagram in discrete system of PLC", IEEE Transaction, Vol. PAS-100, pp-143-153, January 1989.

[6] SubhransuPadhee, Yaduvir Singh "Data Logging and Supervisory Control of Process Using Lab VIEW", Proc. of the IEEE Students Tech. Symp., pp. 329334, Jan 2011.

[7] Xiang fei, ZOU Li hua, "Optimization design of PID controller and its application", 2011 Third International Conference on Measuring Technology and Mechatronics Automation, vol.2, pp. 803-806, Jan 2011.

[8] Yonghong Huang, Nianping Li, YangchunShil, YixunYil, "Genetic Adaptive Control for Drum Level of a Power Plant Boiler", IEEE Computational Eng.
Syst. Applicat. (IMACS), vol.2, pp. 1965-1968, Oct 2006.

[9] Yuanhui Yang, Wailing Yang, Mingchun Wu, Qiwen Yang, and YuncanXue, "A New Type of Adaptive Fuzzy PID Controller", Proceedings of the 8th World Congress on Intelligent Control and Automation, pp. 5306-5310, July 2010.

[10] ZaferAydogmus, OmurAydogmus, "A Web-Based Remote Access Laboratory Using SCADA, IEEE Trans. Edu., vol. 52, issue. 1, pp. 1-7 Feb 2009.

\section{BIOGRAPHIES}

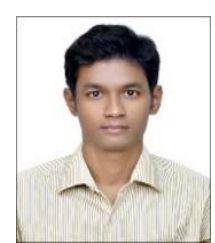

V.Ramprasadhwas born in Erode, India. He received his B.E degree in the department of Electronics \& Instrumentation Engineering from Anna University Chennai in 2010. He is pursuing M.E degree in the department of Control \& Instrumentation Engineering from Anna University Chennai.

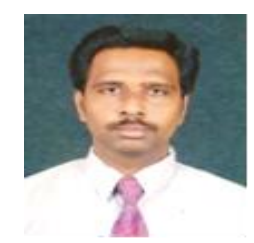

Hari Krishnan. P Was born in Madras (now Chennai). He received his $\mathrm{BE}$ degree in Electrical and Electronics of Madras University in 1997. Received his ME degree in Applied Electronics $\mathrm{He}$ is a Life member of MISTE. Currently he is working as Assistant professor in Anna University, Regional Centre, Coimbatore, His areas of interests include Image processing, Digital signal processing and Instrumentation 